\title{
Information technology (IT) knowledge and skills of accounting graduates : does an expectation gap exist?
}

\begin{abstract}
The present research explores the expectation gap in information technology (IT) skills development in an accounting degree course using grounded theory methodology. Data were collected using multiple qualitative approaches, including interviews; focus groups; observations; and document reviews, focusing on respondents at one traditional university in the UK and involving respondents from one of the big four accounting firms operating in the UK. The findings indicate that some of the required understanding and skills relating to accounting, tax and auditing software is lacking, suggesting an expectation gap. Different opinions concerning who should assume the responsibility for the development of the IT skills of the graduates; the understanding concerning the nature of IT skills; unclear expectations; and a lack of communication among stakeholders in accounting education are the factors perceived to cause the existence of such a gap. The findings also reveal that educators, as major players in the education process, should initiate a platform to promote communication among all stakeholders in educations, including potential employers and students, so that skills needs and expectations can be clearly identified and communicated, thus bridging the gap.
\end{abstract}

Keyword: Expectation gaps; Accounting education; Information technology skills; Innovation and change in higher education 